\title{
The stiff-man syndrome: new pathophysiological aspects from abnormal exteroceptive reflexes and the response to clomipramine, clonidine, and tizanidine
}

\author{
H-M MEINCK, ${ }^{*}$ K RICKER, $\dagger$ B CONRAD* \\ From the Department of Clinical Neurophysiology, University of Göttingen, ${ }^{*}$ and the Department of \\ Neurology, University of Würzburg, $†$ FRG
}

SUMMARY Neurophysiological investigations of a patient suffering from the stiff-man syndrome revealed that exteroceptive reflexes, in particular those elicited from the skin, were excessively enhanced. In contrast, no abnormalities were found within the monosynaptic reflex arc. Clomipramine injection severely aggravated the clinical symptoms whereas diazepam, clonidine, and tizanidine decreased both muscular stiffness and abnormal exteroceptive reflexes. The hypothesis is put forward that the stiff-man syndrome is a disorder of descending brain-stem systems which exert a net inhibitory control on axial and limb girdle muscle tone as well as on exteroceptive reflex transmission. Detection of abnormal exteroceptive reflex activity in conjunction with neuropharmacological testing might help in the diagnosis of this rare disease.

The characteristic clinical features of the stiff-man syndrome have been described by Gordon $e t$ al ${ }^{1}$ based on 45 case histories: progressing (usually symmetrical) stiffness particularly of the axial muscles, fluctuating in intensity, and frequently superimposed with painful spasms evoked by noise or fright. Stiffness disappears during sleep, narcosis, or after administrating neuromuscular blocking agents, and local stiffness is abolished by nerve and ventral root blocks. Neurological examination usually reveals no abnormality except for increased muscle tone, but the deep tendon reflexes may be exaggerated. In many cases diazepam has been reported to have a favourable effect on muscle stiffness. The pathogenesis of the disease is still unknown. Several possible mechanisms have been suggested: psychopathological aetiology, ${ }^{23}$ a brain stem disorder,${ }^{4}$ an imbalance between catecholaminergic and GABAergic descending pathways, ${ }^{5-7}$ increased central drive on $\gamma$ motoneurons, ${ }^{18}$ subnormal function of Renshaw cells, ${ }^{9}{ }^{10} \gamma$ axon parabiosis,,$^{11}$ muscle disease,,${ }^{12}$ and metabolic disorders. ${ }^{13}$ However, Moersch's and Woltman' $\mathrm{s}^{14}$ initial definition has been modified so that the clinical diagnosis "stiff-man syndrome" now comprises a variety of clinically related, but

Address for reprint requests: Dr H-M Meinck, Abteilung für Klinische Neurophysiologie, Neues Klinikum, Robert-Koch-Str. 40, D 3400 Göttingen, FRG.

Received 28 April 1983 and in revised form 11 July 1983 Accepted 14 September 1983 aetiologically different disorders ${ }^{1}$ such as the jerking stiff-man syndrome, ${ }^{15} 16$ cases with CSF and CT abnormalities, ${ }^{17}$ and congenital or even familiar forms. ${ }^{18} 19$ The differential diagnosis includes other rare disorders, such as myositis fibrosa generalisata, ${ }^{20}{ }^{21}$ rigid spine syndrome,,$^{22}$ subacute tetanus ${ }^{23}$ progressive encephalomyelitis with rigidity, ${ }^{24}$ and other syndromes of abnormal muscular activity. ${ }^{25}$

\section{Case report}

In 1963, the patient, a female, then 37 years old, suffered painful cramps and stiffness of the neck, shoulder and leg muscles. In spring 1964 she noted abrupt muscle spasms when the door bell rang or when a glass crashed to the floor. Once she burnt herself while ironing. This caused severe spasms which forced her to press the iron against her forearm and rendered her incapable of removing it. Within one year stiffness developed in the trunk and proximal limb muscles, and her gait became clumsy. Spasms and stiffness were intensified by emotional upset. Her family was reported to be free of disease, particularly of nervous or mental disorders. In 1966, the diagnosis stiff-man syndrome was made. ${ }^{11}$ Since then her complaints and symptoms have remained essentially unaltered. For most of this time, she was treated with diazepam which considerably reduced her symptoms. Repeated interruptions of her drug regimen resulted in intensification of muscular stiffness and spasms. The patient is married and has two healthy children.

Repeated neurological examinations revealed no muscular atrophy, hypertrophy or paresis. Muscle tone and consistency were increased particularly in her neck, trunk, and proximal limb muscles. In her arms flexor tone 
exceeded extensor tone, whereas in her legs flexor and extensor tone were roughly the same. Increased muscle tone could be best described as being a mixture of spasticity and rigidity. Muscle tone was influenced by her alertness and by her momentary emotional state. It increased when she was under stress and decreased when she was drowsy, but was never reduced to normal except during sleep. In an upright standing posture her head was bent forward, her shoulders elevated, her arms flexed and adducted, and her knees and hips slightly flexed. She was unable to recline her head or to lift her arms above her head. Without support she walked stiff-legged and with short steps, the swing of her arms being reduced. She turned about her axis from one step to the other without distortion of the spine. When walking or standing, she had difficulty on uneven ground. In a sitting position any slight shift of her seat caused her to fall. Limb movements were severely disturbed by coactivation of both agonists and antagonists whereas finger and facial movements were performed only with slight clumsiness. Ocular movements and swallowing were normal. The deep tendon reflexes were brisk and symmetrical, and there was no clonus. No pathological cutaneous reflexes were found, but cutaneous stimuli provoked an increase in stiffness and painful, generalised spasms. Unexpected noise (such as loud hand-clapping), fright (caused by, for example, unexpected touch or a sudden jolt) as well as active or passive movements also elicited such spasms. These were characterised by a brisk onset and a slow decrescendo, and involved her facial, trunk and limb muscles (grimace, anteflexion of the head, elevation of the shoulders, adduction and flexion of the arms, opisthotonus, extension of the legs). Sensory disturbances and hyperhidrosis were not observed. Repeated psychiatric study gave no evidence for the existence of any mental disease.

The results of repeated laboratory tests, including examination of cerebrospinal fluid, muscle biopsy (1966 and 1979), EEG, and cranial computed tomography, were normal. In the EMG, a continuous firing of normal motor unit potentials was recorded from various muscles, and could not be suppressed volitionally. Nerve conduction velocities were normal. The electro-nystagmogram, acoustic evoked brain stem potentials, visual and somatosensory evoked potentials were normal; in particular enlarged SSEPs were not observed..$^{16}$ However, the blink reflex was abnormal (see below). The first report on this patient ${ }^{11}$ stated that myoneuronal, neuronal and radicular block as well as narcosis caused muscular stiffness and EMG activity to disappear.

The purpose and nature of the following experiments were explained to the patient in detail, and she gave her informed consent to all the procedures reported below.

\section{Special investigations}

(1) Electromyographic recording of spasms evoked by exteroceptive stimuli: Visual stimuli (irregularly applied stroboscope flashes) failed to evoke distinct motor responses. Unexpected acoustic stimuli, however, elicited rapidly habituating bilateral EMG responses, consisting of an early burst (onset latencies: 25 to $74 \mathrm{~ms}$ in the brachial biceps, and 66 to $312 \mathrm{~ms}$ in the quadriceps muscles, respectively), followed by long-lasting tonic activity. Somatosensory stimuli (electrical impulses delivered to the median nerve at the wrist) elicited non-habituating bursts of EMG activity in homolateral neck, arm and leg muscles with latencies between 20 and $100 \mathrm{~ms}$ (fig 1). Vestibular stimuli were applied during investigation of the postrotational nystagmus and during cold water insufflation into the outer ear. The latter stimulus led to a long-lasting painful contraction of the neck, shoulder and arm muscles with a delay of about $3 \mathrm{~s}$, independent of duration or intensity of the nystagmus. After arresting the motion of the rotating chair, an EMG jerk followed by tonic activity was recorded from the facial and brachial muscles with a latency of $90 \mathrm{~ms}$. This activity was definitely not associated with the onset and intensity of the nystagmus. In general, spasms evoked by acoustic, and particularly by somatosensory stimuli, were so uniform that exaggerated exteroceptive reflex mechanisms were considered to play an important pathogenetic role.

(2) Investigation of various cutaneo-muscular reflex arcs: The blink reflex was elicited by single shocks applied to the right supraorbital nerve at $3 \mathrm{~s}$ intervals and was recorded bilaterally from the orbicularis oculi muscles with needle electrodes (fig 2). With stimulus intensity just above the reflex threshold, the typical responses were observed consisting ipsilaterally of R1 (latency $12 \mathrm{~ms}$ ) and R2 (42 ms) and contralaterally of only R2 (48 ms). A slight increase in stimulus intensity resulted in the typical reduction of the $\mathrm{R} 2$

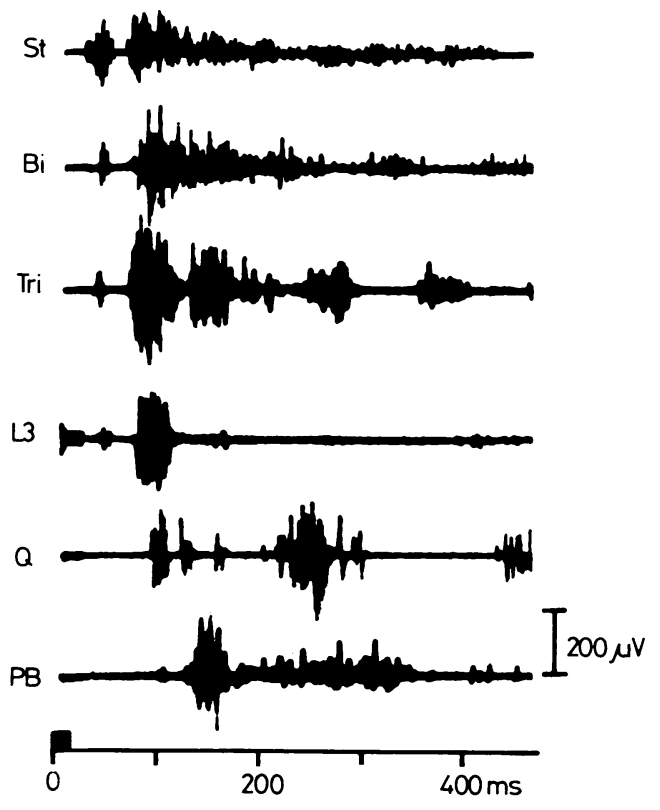

Fig 1 Electromyographic recording of stimulus-induced spasms. Recording with needle electrodes from the left sternocleidomastoid (St), biceps bracnii (Bi), triceps (Tri), paravertebral $L_{3}\left(L_{3}\right)$, quadriceps $(Q)$, and posterior biceps $(P B)$ muscles. Electrical stimulation of the left median nerve at the wrist (train of $20 \mathrm{~ms}$ duration, $400 \mathrm{imp} / \mathrm{s}$, stimulus intensity $1.2 \times T$, recurrence frequency $1 / 10 \mathrm{~s}$ ). Five sweeps superimposed. 

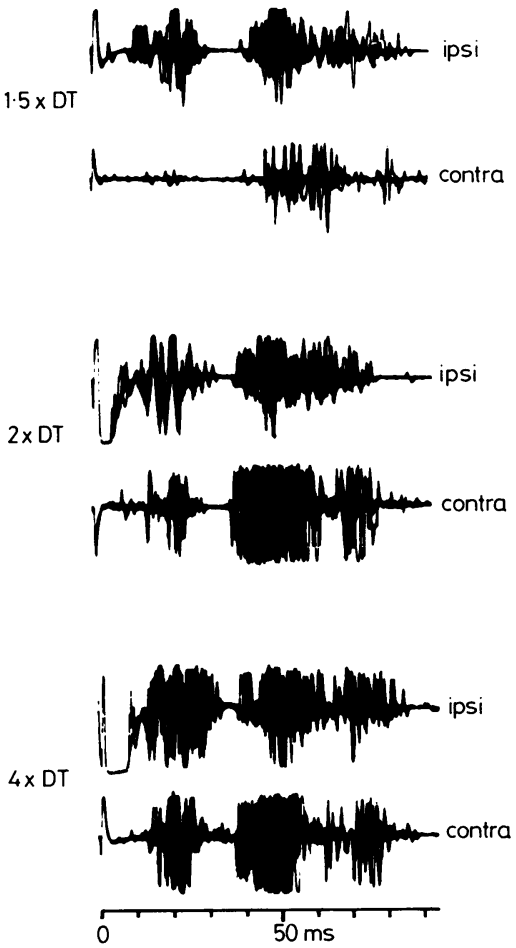

Fig 2 Blink reflex in the ipsi- and contralateral orbicularis oculi muscles elicited by percutaneous single electrical shocks to the supraorbital nerve with increasing stimulus strengths. Five sweeps superimposed. $D T=$ detection threshold. Reflex threshold was at $1.3 \times D T$.

latency $(37 \mathrm{~ms})$. However, a contralateral R1 response (latency: $14 \mathrm{~ms}$ ) occurred. Moreover, on both sides an R3 response occurred with a latency of around $65 \mathrm{~ms}$. Loud clicks $(130 \mathrm{~dB}$ peak $)$ applied at 10 s intervals to either one or both ears elicited weak and desynchronized responses on both sides with a double peak. These responses were far less intense than those elicited by electric shocks and they habituated rapidly.

Cutaneo-muscular reflexes in the hand and leg were elicited by short pulse trains at $3 \mathrm{~s}$ intervals, delivered either to the median nerve at the wrist $(400 \mathrm{imp} / \mathrm{s}, 10 \mathrm{~ms}$ duration; cf. refs 26-29), or to the medial plantar nerve $(400 \mathrm{imp} / \mathrm{s}, 20 \mathrm{~ms}$ duration; refs 29,30 ). Stimulus intensities were adjusted to the threshold $(\mathrm{T})$ of motor fibres supplying the abductor pollicis brevis and flexor hallucis brevis muscles, respectively. The EMG responses were full-wave rectified and summated. ${ }^{31}$ In fig 3, the normal reflex patterns in four representative muscles of the arm (left column) and the leg (right column), respectively, are compared to those obtained from the patient. The recordings from the ipsilateral abductor pollicis brevis, adductor pollicis, biceps brachii, and triceps brachii muscles of a normal subject show that, even at high stimulus intensities, only an $M$ wave, with no reflex activity, is evoked in the abductor pollicis brevis muscle. In the patient, identical stimuli of moderate strength $(1.5 \times \mathrm{T})$ evoked an early burst response in all four muscles at latencies between 20 and $30 \mathrm{~ms}$, followed by a period of electrical silence (for comparison, F wave latencies in the adductor pollicis and abductor pollicis brevis muscles ranged between 28 and $32 \mathrm{~ms}$ ). In the proximal pair of muscles a second desynchronised burst of activity occurred. The reflex threshold of the early reflex components was lower in, and reflex transmission was faster to, the adductor pollicis and biceps brachii muscles, both being considered (physiological) flexors. Moreover, the overall EMG activity in the biceps brachii and adductor pollicis muscles clearly exceeded the activity in the respec-
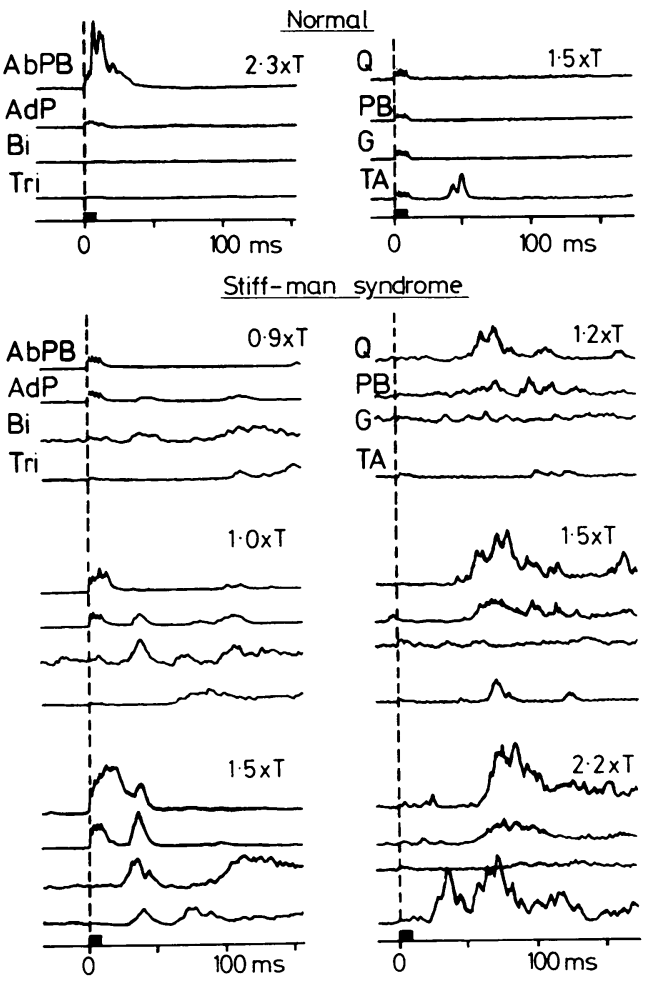

Fig 3 Cutaneo-muscular reflexes of various arm (left column) and leg (right column) muscles, elicited by median nerve stimulation (pulse train: $10 \mathrm{~ms}$ duration, $400 \mathrm{imp} / \mathrm{s}$ ) or by medial plantar nerve stimulation (pulse train: $20 \mathrm{~ms}$ duration, $400 \mathrm{imp} / \mathrm{s}$ ). The onset of stimulation is indicated in each column by a vertical broken line, whereas the stimulus duration is indicated by a horizontal bar on the time scale. Each recording represents eight full-wave rectified and summated responses. Abbreviations: $A b P B=$ abductor pollicis brevis, $A d P=$ adductor pollicis, $B i=$ biceps brachii, Tri = triceps brachii, $Q=$ quadriceps, $P B=$ posterior biceps, $G=$ gastrocnemius, $T A=$ tibialis anterior. $T=A$ a threshold to the abductor pollicis brevis or flexor hallucis brevis muscles, respectively. Polyphasia of the $M$ wave in the $A b P B$ is due to train stimulation. 
tive antagonists. However, tonic after activity was more prominent in the proximal muscles.

Stimulation of the finger nerves revealed an identical reflex activity largely excluding both monosynaptic reflex irradiation from the abductor pollicis brevis muscle afferents and a mirror discharge mechanism ( $F$ wave). Even when the stimulus intensity definitely exceeded the pain threshold, no additional reflex components were elicited; merely a continuous increase of the amplitude of the early and late reflex activity were observed. The stimulus interval (varied between 0.75 and $9.0 \mathrm{~s}$ ) proved to exert no consistent influence on shape or amplitude. Ischaemia of the forearm for 20 min did not affect the early bursts, but decreased the amplitude of the late reflex activity.

Reflex activity in the leg was recorded from the quadriceps, biceps, gastrocnemius, and tibialis anterior muscles. In normal subjects, the tibialis anterior response has a distinctly lower threshold than the biceps, quadriceps and gastrocnemius responses (cf ref 30 ). The quadriceps muscle in particular is recruited only at high stimulus intensities. In the patient, at low stimulus intensities only the proximal muscles were activated, quadriceps activity significantly exceeding the biceps activity. An increase in stimulus intensity resulted in an enhancement of quadriceps and biceps reflex activity and in a desynchronised reflex response in the tibialis anterior, which in comparison with normal values ( $70 \mathrm{~ms} \pm 10 \mathrm{SD}$; cf ref 32$)$ was delayed. Further increase in stimulus intensity led to a successive reduction of the tibialis anterior reflex latency, namely from $290 \mathrm{~ms}(1.2 \times \mathrm{T})$ down to the extremely short latency of $38 \mathrm{~ms}(2.2 \times \mathrm{T})$. However, the reflex response remained prolonged in duration and desynchronised.

A systematic variation of both the stimulus strength and the stimulus interval revealed a successive build-up of the early tibialis anterior reflex component not only with increasing stimulus strengths, but also with shortening of stimulus intervals, indicating an abnormally high demand for spatial (stimulus strength) and temporal (stimulus interval) facilitation in the reflex pathway mediating early tibialis anterior excitation.

(3) Sonomotor reflexes: Sonomotor reflexes ${ }^{33}$ were elicited by a $130 \mathrm{~dB}$ click delivered at irregular intervals of about $10 \mathrm{~s}$ to either one or both ears (fig 4). Sonomotor reflexes consisted of repeated EMG bursts with a rapid decline in both proximal-distal and cranio-caudal direction (fig 4, left column), their latencies in different muscles ranging from 40 to $105 \mathrm{~ms}$. Binaural stimulation proved to be slightly more effective than monaural stimulation. Sonomotor reflexes rapidly habituated, even when a binaural stimulus was repeated at somewhat irregular intervals. Motor responses evoked by acoustic stimuli were less synchronised, had smaller amplitudes and habituated more rapidly than those evoked by somatosensory stimuli.

(4) Investigation of the monosynaptic reflex arc: $\mathrm{H}$ - and Treflex testing was performed mainly in the triceps surae muscle according to the methods described by Hugon. ${ }^{34}$ Both $\mathrm{T}$ - and $\mathrm{H}$-reflexes were increased by the Jendrassik manoeuvre (cf ref 35). The silent periods of the biceps $T$ reflex and of the triceps surae $\mathrm{H}$ - and T-reflexes were within normal limits (105-138 ms). The recruitment curves of the

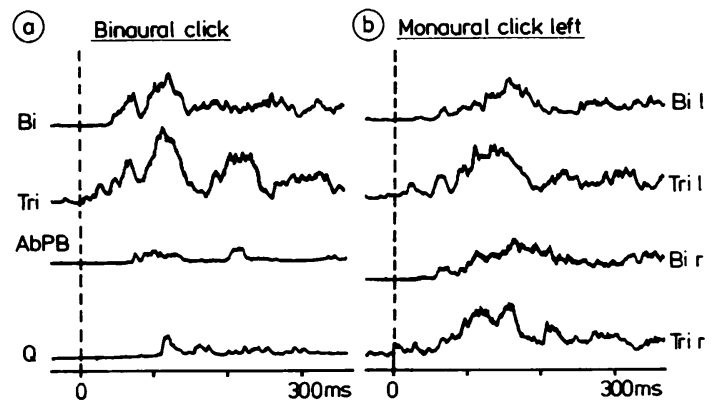

Fig 4 Sonomotor reflexes recorded from left (l) and right (r) arm and leg muscles. For each record, eight consecutive EMG responses were full-wave rectified and summated. For abbreviations see fig 3 .

triceps surae $\mathrm{H}$ - and $\mathrm{M}$-waves, as well as the $\mathrm{H}$-reflex recovery cycle, displayed the normal shape ${ }^{36}{ }^{37}$ the $H / M$ ratio being $0 \cdot 6$. The amplitude of the $\mathrm{H}$-reflex showed a distinct low-frequency depression between $0 \cdot 1 / \mathrm{s}$ and $10 / \mathrm{s}$ stimulus recurrence frequencies. ${ }^{38-40}$ Vibration applied to the achilles tendon $(100 \mathrm{c} / \mathrm{s}, 1 \mathrm{~mm}$ amplitude) caused the amplitude of the H-reflex to decrease to about $60 \%$ of control values, this decrease persisting for about $30 \mathrm{~s}$ after the vibration was stopped. ${ }^{41}$ The F-waves in the abductor pollicis brevis and hypothenar muscles after median and ulnar nerve stimulation were recorded with normal latencies ( 28 and $32 \mathrm{~ms}$, respectively). However, the F-wave in both muscles occurred regularly and had a stable amplitude, even with stimuli which evoked a $15 \% \mathrm{M}$-wave. The amplitude of the F-wave was up to as much as $20 \%$ of the maximal $\mathrm{M}$-wave amplitude. In general, except for the F-wave, normal data were found concerning the monosynaptic reflex arc.

(5) Neuropharmacological investigations: The following drugs were tested for their influence on muscular stiffness and exteroceptive reflex activity: diazepam, tiapride, clomipramine, ${ }^{7}$ tizanidine, and clonidine. Tizanidine (SANDOZ DS 103-282) is a recently developed antispastic drug. Investigations were performed at two day intervals in order to allow for almost complete elimination of the previously injected drug. Generally, drugs were given to the patient in "single-blind" fashion via a $50 \mathrm{ml}$ drip infusion within a period of about 5 mins. Before and after iv drug administration, reflex responses were elicited in either arm or leg muscles in the manner described above (cf fig 3).

Clomipramine $(0.05 \mathrm{mg} / \mathrm{kg}$ body weight) dramatically increased the muscle tone even before the infusion was completed, and the effect lasted throughout the entire evening and the following night. The patient complained of severe and painful cramps in her neck, shoulder and trunk muscles which became as hard as a board. There was a strong tonic activity in the EMG; jerks were not observed. Cramps were so painful, that reflex investigations could not be performed. Intravenous injection of $10 \mathrm{mg}$ diazepam reduced painful muscular cramps, but did not completely alleviate them. An additional dose of $60 \mathrm{mg}$ diazepam was given orally during the evening and the subsequent night in order to allow the patient to sleep without cramps. 
After tizanidine $(0.005 \mathrm{mg} / \mathrm{kg})$ the patient's muscle tone was noticeably reduced. She was able to walk unimpeded and had no difficulty in lifting her arms above her head and rotating them. Figure 5 shows reflex responses of the leg muscles obtained at various intervals before and after the start of tizanidine administration. Tizanidine largely suppressed abnormal reflex activity, suppression reaching a plateau maximum between 10 and 20 min after the onset of administration. This drug in the above stated dosage proved to be about as effective as $10 \mathrm{mg}$ diazepam. Administration of tizanidine, however, was followed by a $30 \mathrm{mmHg}$ drop in blood pressure. Both diazepam and tizanidine were investigated twice within a period of nine months, the results each time being almost identical. The effect of clonidine $(0 \cdot 0025$ $\mathrm{mg} / \mathrm{kg}$ ) was basically similar to the effect of tizanidine. Repeated injections of a placebo and of tiapride $(8 \cdot 3 \mathrm{mg} / \mathrm{kg})$ failed to show any effect on abnormal reflex activity or increased muscles tone.

On the basis of the above results, we changed the drug treatment from a combination of clonazepam $(8 \mathrm{mg} / \mathrm{d})$ and diazepam $(40 \mathrm{mg} / \mathrm{d})$ to tizanidine $(6 \mathrm{mg} / \mathrm{d})$ alone. This regimen was satisfactory for a period of about seven months, allowing the patient to take short walks and to go shopping by herself.
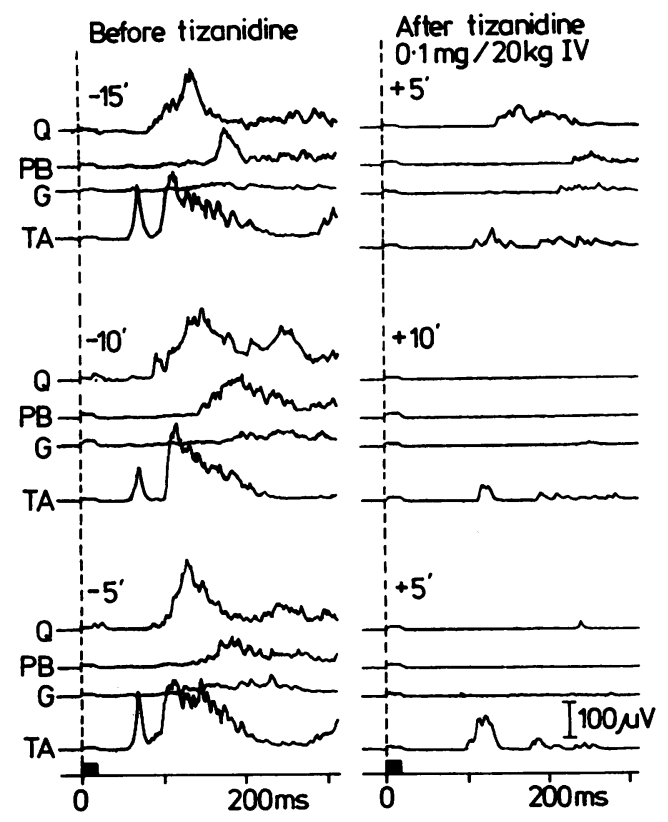

Fig 5 Effect of tizanidine $0 \cdot 1 \mathrm{mg} / 20 \mathrm{~kg}$ iv on cutaneomuscular reflex activity in the leg elicited by medial plantar nerve stimulation (pulse train: $400 \mathrm{imp} / \mathrm{s}, 20 \mathrm{~ms}$ ). Stimulus intensity and interval were fixed at $2.0 \times T$ and $3 s$, respectively, throughout the whole experiment. Layout and abbreviations as in fig 3. Recordings were made 15, 10, and 5 minutes before and 5, 10 and 50 minutes after the start of tizanidine infusion.

\section{Discussion}

The general characteristics of the grossly exaggerated responses to exteroceptive stimuli were abnormally short transmission times and the occurrence of abnormal excitatory reflex phases in face, arm and leg muscles. Both phenomena have not been observed in any other disorder with increased muscle tone, for example spasticity or rigidity (cf ref. 29). Exteroceptive stimuli showed a rank order of effectiveness in evoking abnormal reflex responses: somatosensory stimuli were the most effective, followed by acoustic stimuli. Visual stimuli failed to exert any significant responses. The same was probably true of vestibular stimuli, the distinct increase in muscle tone to caloric stimulation being an unspecific "reticular" effect (cf ref. 42) rather than specifically vestibular, as no such tonic response was observed during the post-rotational nystagmus.

Exaggerated exteroceptive reflexes, at a first glance, might be suspected of being due to an increased central drive onto spinal $\alpha$ motoneurons. Such an increased central drive is, however, easily performed by normal subjects through more or less intensive activation of the respective muscles. We never observed distinct and early responses of this type to cutaneous or mixed nerve stimulation in normal subjects, even when the muscles were activated. ${ }^{29}{ }^{30}$ Therefore, we assume that transmission and central processing of exteroceptive information in the stiff-man syndrome differs from that in the normal subject, resulting in an increased motoneuronal excitability rather than being caused by it. Consequently, the question must be raised as to whether the increased muscle tone is-at least partly - the result of an unrestrained transmission of afferent impulses to $\alpha$ motoneurons. Further evidence in support of this view is derived from ischaemic and procaine nerve blocks which normalise muscle tone (see below).

In contrast to exteroceptive reflexes, monosynaptic reflexes were normal. This is in agreement with other authors who have investigated the $\mathrm{H} / \mathrm{M}$ ratio, the silent period, the H-reflex recovery curve, and recurrent inhibition. ${ }^{78}{ }^{43}$ These observations indicate that the increase in muscle tone in the stiff-man syndrome can be differentiated from spastic muscle tone by means of neurophysiological techniques. ${ }^{35-41}$ As there was no evidence for alterations of monosynaptic transmission, the distinct enhancement of the F-wave might be considered to be the result of an increased central drive directly to motoneurons. However, both the F-wave and the early cutaneo-muscular reflex response showed a similar latency. Therefore, oligosynaptic reflex effects from concomitantly stimulated large skin 
afferents must be considered as a possible source of error concerning the F-wave amplitude.

These findings clearly disagree with those pathogenetic hypotheses which consider the disorder a mental, ${ }^{23}$ muscle,,$^{12}$ or metabolic ${ }^{13}$ disorder. Moreover, a disease of the $\gamma$ motoneurons or the $\gamma$ axons, ${ }^{1811}$ increasing the muscle tone via the muscle spindles, is hardly conceivable in the presence of normal monosynaptic reflex mechanisms and distinctly abnormal exteroceptive reflexes. A key experiment in support of the " $\gamma$-hypothesis" was the local normalisation of the thigh muscle tone after differential procaine block of the femoral nerve, which was also seen in our patient. ${ }^{11}$ However, such a differential block effects not only $\gamma$ efferents but inevitably also afferent fibres of equal (or even shorter) internodal lengths. ${ }^{44}$ Moreover, the " $\gamma$ hypothesis" does not fit in with the clinical picture, because muscle groups with a high proportion of spindles, for example, the small muscles of the hand and foot, are noticeably less afflicted than the trunk and proximal limb muscles, which have a lower spindle content ${ }^{45-47}$ Considering the Renshaw cell hypothesis, ${ }^{910}$ we found no evidence of subnormal function of Renshaw cells. This is in agreement with other authors who have investigated inhibitory functions ascribed to Renshaw cells. ${ }^{78}$ Moreover, if subnormal function of Renshaw cells in the stiff-man syndrome is postulated, one is inevitably obliged to propose a differential distribution of Renshaw cell effects in proximal and distal motor nuclei. This, however, has never been observed.

Most recent authors agree that the pathophysiological basis of the stiff-man syndrome is abnormal function of certain brain-stem structures..$^{4}{ }^{8}{ }^{43}$ Direct evidence for such a location is weak. There is, however, some indirect evidence which justifies such an assumption 458161748 Our observations, particularly the homologous changes of cutaneo-muscular reflexes in the face, the arms, and the legs (that is, in regions which are severely involved as well as in regions which are clinically less involved), suggest a systematic disturbance of the transmission to motoneurons. This might, indeed, indicate a defect in the control of the respective reflex pathways from the brain-stem rather than for example, a diffuse interneuron disease such as spinal rigidity (cf refs 49 , 50).

Rapidly injected clomipramine severely aggravated the clinical symptoms' ${ }^{7}$ whereas diazepam, clonidine, and tizanidine normalised both the muscle tone and the exteroceptive reflex transmission. The latencies of the effects of these drugs were short enough to exclude an action of metabolites of the respective drugs. However, it is not clear whether the effects of these drugs on synaptic transmission in the motor systems involved are direct or indirect. Clomipramine inhibits the neuronal re-uptake of serotonin and noradrenaline, resulting in an transmitter-excess at the synapse. The aggravating effect of clomipramine, therefore, suggests an increased activity of a central serotonergic or noradrenergic system. Clonidine stimulates central $\alpha_{2}$-adrenoceptors resulting in feedback inhibition of noradrenaline release..$^{51}$ This effect suggests involvement of a central noradrenergic system in the stiff-man syndrome, which is suppressed by clonidine. The observed correlation between 3-methoxy-4-hydroxyphenylgycol excretion and clinical symptoms, ${ }^{6}$ as well as the well-known interaction of tricyclic antidepressants and clonidine upon central blood pressure regulation, ${ }^{52}$ might further support this view. Possibly, the effects of tizanidine are neuropharmacologically related to those of clonidine, tizanidine being originally developed as a centrally acting antihypertensive drug, its cardiovascular side-effects resembling those of clonidine (communication by SANDOZ). The beneficial action of diazepam might be explained as being either the result of inhibition of central catecholamine neurones ${ }^{53}$ or of activation of GABAergic mechanisms, ${ }^{54}$ or of both.

According to the clinical, neurophysiological and neuropharmacological features of the disease, the brain stem structures in question must meet the following criteria:

1. They must steer the movements of the axial, girdle and proximal limb musculature, but they may not have much influence upon the movements of the distal limb and facial musculature, and no influence at all on the extraocular motor nuclei.

2. They must exert a net inhibitory control on cutaneo-muscular reflex transmission in spinal and brain-stem pathways.

3. They must be influenced-directly or indirectly-by monoaminergic mechanisms.

With these criteria in mind, the group of medially descending brain stem pathways (group A brain stem pathways according to ref 55) or the pathways descending from the catecholaminergic brain-stem neurons may be regarded as being the most probable. Our present knowledge on the motor functions of these pathways is limited (for recent reviews see refs 55-58). However, concerning our neurophysiological and neuropharmacological findings, there are several striking similarities with the observations of Lundberg and his co-workers (for references see ref 57) on the influence of noradrenergic mechanisms upon flexor reflexes: the activation of descending noradrenergic systems leads to a closing of shortlatency and to an opening of long-latency flexor reflex pathways. Abnormal long-latency flexor reflex 
effects were definitely present in our patient (see figs 2 and 3 ), and they were blocked after administration of tizanidine, clonidine, and diazepam. However, the coincidence is limited: short-latency pathways in our patient reacted in exactly the same way, they were primarily open and closed after the administration of the above mentioned drugs.

Damage to the group of medially descending brain stem pathways (mainly those descending from the pontine and medial medullary tegmentum, the vestibular nuclei, the mesencephalic reticular formation, the superior colliculus, and the interstitial nucleus of Cajal) in the monkey ${ }^{59}$ leads to motor deficits characterised by immobility of the head, trunk and limb girdle, adduction and flexion of the arms, elevation of the shoulders, difficulties in avoiding obstacles, and clumsiness of arm and leg movements. The animals investigated were unable to compensate for a slight shift of the ground, and startling sounds often caused them to fall down. Animals walking without support moved with adducted limbs and a narrow-based gait. Skilled finger movements, however, remained largely unaffected. Neurophysiological investigations were not performed with these animals, but the clinical picture certainly resembles that of our patient. It is, therefore, most tempting to focus future research on these brain stem systems. It is to be hoped that the neurophysiological and neuropharmacological methods described may help to further understand the pathophysiology of the disease, and to differentiate better between the stiff-man syndrome and related disorders.

We thank our patient Ms IB, for her friendly cooperation during this investigation. We also wish to thank Profs HG Mertens and W Poser for valuable and critical discussion, Ms K Lünser for secretarial help and $\mathrm{Mr}$ and Mrs $\mathrm{R}$ Krebs for revision of the English manuscript. This work was supported by the Deutsche Forschungsgemeinschaft (SFB 33).

\section{References}

${ }^{1}$ Gordon EE, Januszko DM, Kaufman L. A critical survey of stiff-man syndrome. Am J Med 1966;42:582-99.

${ }^{2}$ Fogarty JP. The stiff-man syndrome. J Irish Med Assoc 1959;45:44-6.

${ }^{3}$ Heiligman R, Paulson MJ. The stiff man syndrome: A psychiatric disease? Int J Psychiatry Med 1967;7: 363-71.

${ }^{4}$ Cobb J. Stiff man syndrome: Is the lesion at spinal cord or brain stem level? Proc R Soc Med 1974;67:1065-6.

${ }^{5}$ Guilleminault C, Sigwald J, Castaigne P. Sleep studies and therapeutic trial with L-Dopa in a case of stiffman syndrome. Eur Neurol 1973;10:89-96.

${ }^{6}$ Schmidt RT, Stahl SM, Spehlmann R. A pharmacologic study of the stiff-man syndrome. Neurology (Minneap) 1975;25:622-6.

${ }^{7}$ Stöhr M, Heckl R. Das Stiff-man-Syndrom. Arch Psychiat Nervenkr 1977;223:171-80.

${ }^{8}$ Boiardi A, Crenna P, Bussone G, Negri S, Merati B. Neurological and pharmacological evaluation of a case of stiff-man syndrome. J Neurol 1980;223:127-33.

${ }^{9}$ Howard F. A new and effective drug in the treatment of stiff-man syndrome. Mayo Clin Proc 1963;38:203-12.

${ }^{10}$ Olafson RA, Mulder DW, Howard FM. "Stiff-man" syndrome: A review of the literature, report of three additional cases and discussion of pathophysiology and therapy. Mayo Clin Proc 1964;39:131-44.

${ }^{11}$ Mertens HG, Ricker K. Übererregbarkeit der $\gamma$ Motoneurone beim "Stiff-man"-Syndrom. Klin Wschr 1968;46:33-42.

12 Yarom R. Chaco J, Steigbuegel D. Ultrastructure of muscle in stiff-man syndrome. Virchows Arch (Pathol Anat) 1974;362:207-21.

${ }^{13}$ Price TML, Allott EH. The stiff man syndrome. Br Med J 1958;1:682-5.

${ }^{14}$ Moersch FP, Woltman HW. Progressive fluctuating muscular rigidity and spasm ("stiff-man" syndrome): Report of a case and some observations in 13 other cases. Mayo Clin Proc 1956;31:421-7.

${ }^{15}$ Alberca R, Romero M, Chaparro J. Jerking stiff-man syndrome. J Neurol Neurosurg Psychiatry 1982; 45:1159-60.

${ }^{16}$ Leigh PN, Rothwell JC, Traub M, Marsden CD. A patient with reflex myoclonus and muscle rigidity: "jerking stiff-man syndrome". J Neurol Neurosurg Psychiatry 1980;43:1125-31.

${ }^{17}$ Maida E, Reisner T, Summer K, Sandor-Eggert H. Stiffman syndrome with abnormalities in CSF and computerized tomography findings. Arch Neurol 1980;37:182-3.

${ }^{18}$ Sander JE, Layzer AB, Goldsobel AB. Congenital stiffman syndrome. Ann Neurol 1980;8:195-7.

${ }^{19}$ Klein R, Haddow JE, DeLuca C. Familial congenital disorder resembling stiff-man syndrome. Am J Dis Child 1972:124:730-1.

${ }^{20}$ Whalen RE, Comps JJ, Deiss WP. "Stiff-man" syndrome. Am J Med 1959;27:678-81.

${ }^{21}$ Ricker K, Seitz D, Trostdorf E. Myositis fibrosa generalisata and "stiff-man" syndrome. Eur Neurol 1970;3:13-27.

${ }^{22}$ Vogel P, Goebel HH, Seitz D. Rigid spine syndrome in a girl. J Neurol 1982;228:259-65.

${ }^{23}$ McQuillen MP, Tucker K, Pellegrino ED. Syndrome of subacute generalized muscular stiffness and spasm. Arch Neurol 1967;16:165-74.

${ }^{24}$ Whiteley AM, Swash M, Urich H. Progressive encephalomyelitis with rigidity. Brain 1976;99:27-42.

${ }^{25}$ Valli G, Barbieri S, Cappa S, Pellegrini G, Scarlato G. Syndromes of abnormal muscular activity: overlap between continuous muscle fibre activity and the stiff man syndrome. J Neurol Neurosurg Psychiatry 1983;46:241-7.

${ }^{26}$ Caccia MR, McComas AJ, Upton ARM, Blogg T. Cutaneous reflexes in small muscles of the hand. $J$ Neurol Neruosurg Psychiatry 1973;36:960-77.

${ }^{27}$ Conrad B, Aschoff JC. Effects of voluntary isometric and 
isotonic activity on late transcortical reflex components in normal subjects and in hemiparetic patients. $E E G$ Clin Neurophysiol 1977;42:107-16.

${ }^{28}$ Garnett R, Stephens JA. The reflex responses of single motor units in human first dorsal interosseous muscle following cutaneous afferent stimulation. J Physiol (London) 1980;303:351-64.

${ }^{29}$ Meinck HM, Benecke R, Küster S, Conrad B. Cutaneomuscular (flexor) reflex organization in normal man and in patients with motor disorders. In: Desmedt JE, ed. Motor Control in Health and Disease. New York: Raven 1983:787-96.

${ }^{30}$ Meinck HM, Piesiur-Strehlow B, Koehler W. Some principles of flexor generation in human leg muscles. EEG Clin Neurophysiol 1981;52:140-50.

${ }^{31}$ Gassel MM, Ott KH. Motoneuron excitability in man: A novel method of evaluation by modulation of tonic muscle activity. EEG Clin Neurophysiol 1970;29: 190-5.

${ }^{32}$ Fisher MA, Shahani BT, Young RR. Electrophysiologic analysis of the motor system after stroke: the flexor reflex. Arch Phys Med Rehabil 1979;60:7-11.

${ }^{33}$ Meier-Ewert K, Gleitsmann K, Reiter F. Acoustic jaw reflex in man: its relationship to other brain-stem and micro-reflexes. EEG Clin Neurophysiol 1974;36: 629-37.

${ }^{34}$ Hugon M. Methodology of the Hoffmann reflex in man. In: Desmedt JE, ed. New Developments in Electromyography and Clinical Neurophysiology. Vol. III. Basle: Karger, 1973;277-93.

${ }^{35}$ Scherrer J, Rondot P, Korn H, Metral S. Etude accélérométrique et EMG des mouvements anormaux et des réflexes pathologiques. Sem Hop (Paris) $1968 ; 44: 911-9$.

${ }^{36}$ Paillard J. Réflexes et Régulations d'Origine Proprioceptive chez l'Homme. Paris: Arnette, 1955.

${ }^{37}$ Straßburg HM, Oepen G, Thoden U. The late facilation in H-reflex recovery cycles in different pyramidal lesions. Arch Psychiat Nervenkr 1980;228:197-204.

${ }^{38}$ Ishikawa K, Ott K, Porter RW, Stuart D. Low frequency depression of the $\mathrm{H}$ wave in normal and spinal man. Exp Neurol 1966;15:140-56.

${ }^{39}$ Ioku M, Nakatani S, Oku Y, Jimai D. The H-reflex study with high frequency stimulation. Electromyography 1969;9:319-27.

${ }^{40}$ Reichel G, Mühlau G, Stahl J. H-Reflex-Untersuchungen mit Reizserien bei Gesunden und bei spastischen Paresen. EEG EMG 1972;3:178-81.

${ }^{41}$ Delwaide PJ. Étude expérimentale de l'Hyperréflexie Tendineuse en Clinique Neurologie. Brussels: Arscia, 1971.

${ }^{42}$ Delwaide PJ, Juprelle M. The effects of caloric stimulation of the labyrinth on the soleus motor pool in man. Acta Neurol Scand 1977;55:310-22.

${ }^{43}$ Mamoli B, Heiss WD, Maida E, Podreka J. Electrophysiological studies on the "stiff-man" syndrome. $J$ Neurol 1977;217:111-21.

${ }^{44}$ Franz DN, Perry RS. Mechanisms for differential block among single myelinated and non-myelinated axons by procaine. J Physiol (London) 1974;236:193-210.

${ }^{45}$ Voss H. Untersuchung über die Zahl, Anordnung und Länge der Muskelspindeln in den Lumbricalmuskeln des Menschen und einiger Tiere. Z Mikr Anat Forsch 1937;42:509-24.

${ }^{46}$ Voss H. Zahl und Anordnung der Muskelspindeln in den unteren Zungenbeinmuskeln, dem M. sternocleidomastoideus und den Bauch- und tiefen Nackenmuskeln. Anat Anz 1958;105:265-75.

${ }^{47}$ Cooper S. Muscle spindles and other muscle receptors. In: Bourne GH, ed. The Structure and Function of Muscle. Vol. I. New York: Academic Press, 1960: 381-420.

${ }^{48}$ Franck G, Cornette M, Grisar T, Moonen G, Gerebtzoff MA. Le syndrome de l'homme raide. Acta Neurol Belg 1974;74:221-40.

${ }^{49}$ Howell DA, Lees AJ, Toghill PJ. Spinal internuncial neurones in progressive encephalomyelitis with rigidity. J Neurol Neurosurg Psychiatry 1979;42:773-85.

${ }^{50}$ Davis SM, Murray NMF, Diengdoh JV, Galea-Debono A, Kocen RS. Stimulus-sensitive spinal myoclonus. $J$ Neurol Neurosurg Psychiatry 1981;44:884-8.

${ }^{51}$ Starke K. Regulation of noradrenaline release by presynaptic receptor systems. Rev Physiol Biochem Pharmacol 1977;77:1-124.

${ }^{52}$ van Zwieten PA, Pauer M, van Spanning HW, de Langen C. Interaction between centrally acting hypotensive drugs and tricyclic antidepressants. Arch Int Pharmacodyn 1975;214:12-30.

${ }^{53}$ Corrodi H, Fuxe K, Lidbrink P. Minor tranquilizers, stress and central catecholamine neurons. Brain Res 1971;29:1-16.

${ }^{54}$ Haefely W, Kulcsaf́ A, Möhler H, Pieri L, Polc P, Schaffner R. Possible involvement of GABA in the central actions of Benzodiazepines. In: Costa $\mathrm{E}$, Greengard P, eds. Mechanism of Action of Benzodiazepines. New York: Raven, 1975:131-51.

${ }^{55}$ Kuypers HGJM. Anatomy of the descending pathways. In: Brookhart JM, Mountcastle VB, Brooks VB, Geiger SR, eds. Handbook of Physiology, Section 1, Vol. II. Bethesda, Md: American Physiological Society, 1981:597-666.

${ }^{56}$ Baldissera $F$, Hultborn $H$, Illert $M$. Integration in the spinal cord. In: Brookhart JM, Mountcastle VB, Brooks VB, Geiger SR, eds. Handbook of Physiology, Section 1, Vol. II. Bethesda, Md: American Physiological Society, 1981:509-95.

${ }^{57}$ Lundberg A. Multisensory control of spinal reflex pathways. In: Granit R, Pompejano O, eds. Progress in Brain Research. Vol. 50. Amsterdam: Elsevier, 1979:11-28.

${ }^{58}$ Wilson VJ, Peterson BW. Vestibulospinal and reticulospinal systems. In: Brookhart JM, Mountcastle VB, Brooks VB, Geiger SR, eds. Handbook of Physiology, Section 1, Vol. II. Bethesda, Md: American Physiological Society, 1981:667-702.

${ }^{59}$ Lawrence DG, Kuypers HGJM. The functional organization of the motor system in the monkey II. Brain 1968;91:15-36.

${ }^{60}$ Meinck HM, Benecke R, Ricker K, Conrad B. Polygraphische Bewegungs- und Reflexanalyse beim Stiff-man Syndrom. EEG EMG 1980;11:242.

${ }^{61}$ Meinck HM, Benecke R, Conrad B, Ricker K. The stiffman syndrome: an extrapyramidal disease? Excerpta Medica International Congress Series 1981;548:100. 